\title{
Map Usage on Smartphones and Acquisition of Spatial Knowledge
}

SHINGAKI, Noriko ${ }^{\mathrm{a}, *}$

a Seijo University, Tokyo, Japan, shingaki@Qomo.org

* Corresponding author

Keywords: Map Usage, Cognitive Map

\begin{abstract}
:
The study of spatial cognition has been one of important research domain for geographic information science. Recently our circumstance to acquire geographic information have been changed (e. g. Wakabayashi, itoh, \& Nagami, 2011), so It is important to clarify the influence of the environmental change in the acquisition of spatial knowledge.

In this study we revealed relationships between the tendency to use geospatial information on smartphones and the acquisition of spatial knowledge. Currently, most people own smartphones and obtain transit information from them, such as train transit planners and Google maps, when they visit a place for the first time. The usage of geospatial information on smartphones significantly affects the accuracy of cognitive maps. Maps, including train route maps, present locational information widely, in a two-dimensional space; thus, users can understand the relationships among locations over a wide area. In contrast, the small displays of smartphones permit the concurrent viewing of only small areas of geospatial information. Locational information, such as the results of transportation planner applications, are typically described in a one-dimensional space, from start point to goal point.

Little is known regarding the effect of accessing geospatial information through smartphones on cognitive maps. The purpose of this study was to determine how people obtain locational information and how the experience of accessing locational information through smartphones affects the acquisition spatial knowledge regarding locations of places. To understand this spatial knowledge acquisition, we conducted two experiments.
\end{abstract}

\section{Experiment 1}

First, we conducted a questionnaire study of 37 university students ( age: $M=20.64$ years, $S D=1.16$ ) living in the suburbs of Tokyo who were attending universities in Tokyo and 28 older adults (age: $M=53.48$ years, $S D=3.20$ ), most of whom were the parents of the university students. To reveal the participants' geospatial knowledge of Tokyo prefecture, they completed a questionnaire that asked them to locate seven major places in Tokyo, such as landmarks and railroad stations in Tokyo prefecture, relative to two reference points, namely Shinjuku station and Mt. Takao, which were provided on the blank questionnaire sheet. Additionally, we asked participants about their map usage, for example what kinds of maps they used when they went out somewhere at first time and how they accessed those maps such as google map on PC and train route maps on paper and transportation planner applications on smartphones, and so on.

\section{Results 1}

The results indicated that the main means to check the destination or route when first traveling to a location was smartphone applications. This was true for university students and the older cohort. 
More older people than university students used smartphones as a primary method of finding a route to destinations.

To examine the effect of smartphone use, we obtained bidimensional correlations $R$ (see Wakabayashi, et al. , 2011) between the configuration of places as plotted by participants and the actual configuration of the places. Correlation for university students was $R=.546$ and that for the older cohort was $R=.819$.

. This result indicates that the accuracy of the spatial knowledge of the older cohort was better than that of the university students.

\section{Experiment 2}

In the second experiment, we administered a questionnaire to 69 university students ( age: $M=$ 20.96 years, $S D=1.14$ ) living in the suburbs of Tokyo, who were attending universities in Tokyo. The questionnaire was composed of four sheets. Each sheet asked the participant to locate seven major places within different geographic scales. The first sheet queried the locations of shops and buildings in their university town, the second sheet queried the locations of major landmarks and railroad stations in Tokyo, the third sheet queried the location of the capital cities of prefectures in the Kanto region, and the fourth sheet queried the location of capital cities of prefectures in Japan. On each sheet, two reference points were initially provided.

\section{Results 2}

The results of the second experiment indicated that the main means by which university students checked a destination or route for the first time was via smartphone applications.

To examine the effect of smartphone usage, we analyzed correlations between the configuration of places as plotted by participants and the actual configuration of those places. These correlations are shown in Table 1 for each questionnaire sheet. Table 1 indicates that the accuracy of spatial knowledge of landmarks and train stations of the Yamanote line were least precise of all geographic scales assessed.

Table 1. Correlations between suggested and actual landmark locations for four geographic scales.

\begin{tabular}{|c|c|c|c|}
\hline Places plotted & $\begin{array}{l}\text { Scale of } \\
\text { questionnaire } \\
\text { sheet }\end{array}$ & $\begin{array}{l}\text { Assumed means by which } \\
\text { spatial information was } \\
\text { acquired }\end{array}$ & $\begin{array}{l}\text { Bidimensional } \\
\text { Correlation } R\end{array}$ \\
\hline $\begin{array}{l}\text { University } \\
\text { neighborhood }\end{array}$ & 1 to 1,700 & Walking around actual place & .751 \\
\hline $\begin{array}{l}\text { Landmarks and train } \\
\text { stations around } \\
\text { Yamanote line }\end{array}$ & 1 to 100,000 & $\begin{array}{l}\text { Maps and transit } \\
\text { information via smartphone } \\
\text { applications }\end{array}$ & .576 \\
\hline $\begin{array}{l}\text { Capital cities of the } \\
\text { prefectures in the } \\
\text { Kanto region }\end{array}$ & 1 to $1,000,000$ & Via Kanto region maps & .678 \\
\hline $\begin{array}{l}\text { Capitals cities of the } \\
\text { prefectures in all of } \\
\text { Japan }\end{array}$ & 1 to $1,500,000$ & Maps of all of Japan & .750 \\
\hline
\end{tabular}




\section{Discussion}

The results show that the usage of geospatial information on smartphones may have a significant effect on the accuracy of university students' cognitive maps. University students did not have precise cognitive maps of landmarks and train stations of the Yamanote line, which they encountered on a daily basis.

Prior to the advent of smartphones, people used to access train station information in Tokyo using paper maps and route maps. Therefore, it was possible to understand the positional relationships among the Yamanote line stations in Tokyo. However, in recent years, narrow search ranges favored by smartphone users and the use of topological location information by train transfer search may hinder the accurate formation of individual cognitive maps.

\section{Acknowledgments}

This study was supported by JSPS KAKENHI Grant Number JP17H00839. Part of the data in this study were collected by Kaoruko Toda, as part of her graduate thesis. 